\title{
The Potential 'O-GlcNAc-P'om'
}

\author{
\| Soo Moon ${ }^{1,2} \star$, HyunSook Lee ${ }^{2}$ and Hyung Jong Lee ${ }^{3}$ \\ ${ }^{1}$ Department of Anatomy, College of Medicine, Dongguk University, Gyeongju 780-714, Korea \\ ${ }^{2}$ Neuroscience Section, Medical Institute of Dongguk University, Gyeongiu 780-714, Korea \\ ${ }^{3}$ Department of Obsterics and Gynecology, Dongguk University College of Medicine, Gyeongiu 780-714, Korea
}

Received February 19, 2012 /Revised February 27, 2012 /Accepted February 27, 2012

\begin{abstract}
The addition and removal of $N$-acetylglucosamine (GlcNAc) molecules on serine or threonine residues of a protein is called $O$-GlcNAcylation. This post-translational modification occurs on both cytoplasmic and nuclear protein, and is fast and reversible as comparable to phosphorylation. In contrast to the phospho-signaling cycles, this emerging moon-lightening signaling is cycled by only two enzymes, $O$-GlcNAc transferase (OGT) and $O$-GlcNAcase (OGA). The simple machinery is a good evolutionary adaptation of a cell for quick accommodation to continuously fluctuating intra- and extracellular microenvironments. Rather than "switching" on or off a specific proteins - this would be done by phosphorylation where numerous specific kinases and phosphatases are involved - $O$-GlcNAcylation would play a "rheostat" which would be much more delicately increase or decrease the efficacy of signal transductions in response to cellular nutrient and stress conditions. Interestingly, recent evidence indicates that $O$ GlcNAc is further modified by phosphorylation. The $O$-GlcNAc-P will upgrade the modulation efficiency of cellular processes to continuous 'analogue' level. So far, only one protein AP180 was reported to have O-GlcNAc-P on Thr310. But, proteomic data from our laboratory indicate that there are multiple $O$-GlcNAc-P proteins, constituting "O-GlcNAc-P'om". This will focus on the possibility of existence of "O-GlcNAc-P' om".
\end{abstract}

Key words : NAGK, OGA, OGT, O-GlcNAc, O-GlcNAc-P

\section{Introduction}

The $O$-linked attachment of a single monosaccharide $\beta$ - $N$-acetyl-D-glucosamine (GlcNAc) to serine and threonine residues (O-GlcNAc) was first reported in 1984 [26]. Since then, this type of post-translational modification of proteins (i.e., $O$-GlcNAcylation) was found in many different proteins. Most recently, a most advanced technology, the 'Click' chemistry, followed by LC-MS/MS afforded the identification of around $1500 \mathrm{O}$-GlcNAc proteins from a single cell line [9]. The $O$-GlcNAcylation is atypical, different from the classical glycosylation. Firstly, $O$-GlcNAcylated proteins are nucleocytoplasmic, whereas the classical glycosylation occurs on secreted extracellular proteins and on the extracellular segments of integral membrane proteins.

\footnotetext{
*Corresponding author

Tel : +82-54-770-2414, Fax : +82-54-770-2447

E-mail : moonis@dongguk.ac.kr

This is an Open-Access article distributed under the terms of the Creative Commons Attribution Non-Commercial License (http://creativecommons.org/licenses/by-nc/3.0) which permits unrestricted non-commercial use, distribution, and reproduction in any medium, provided the original work is properly cited.
}

Secondly, $O$-GlcNAcylation is a single molecule (i.e., GlcNAc) addition, whereas the classical glyco-moieties are very complex. Thirdly, $O$-GlcNAcylation is a dynamic and reversible process of a single $O$-GlcNAc moiety [14]. In contrast, the classical glycosylation requires a series of irreversible addition reactions which occur in a co-translational or post-translational manner. Lastly, the sugar moiety $O$-GlcNAc was until recently thought to be a terminal modification, that is, the $O$-GlcNAc is not additionally modified in any way. This latter thought is now challenged and recent evidence indicates a possibility of phosphorylation on the $O$-GlcNAc to produce $O$-GlcNAc-P. Multiple $O$-GlcNAc-P proteins will constitute the dubbed 'O-GlcNAc-P'om'. This review will present theoretical and experimental evidence that supports the existence of $O$-GlcNAc-P'om.

\section{The O-GlcNAcylation}

The GlcNAc molecule is energized by a high-energy covalent bond with uridine diphosphate (UDP). The transfer of the energized GlcNAc moiety in the UDP-GlcNAc onto a protein is catalyzed by the UDP-GlcNAc:polypeptide $O-\beta$ 
- $N$-acetyl glucosaminyltransferase, or $O$-GlcNAc transferase (OGT). Conversely, the $O-\beta-N$-acetylglucosaminidase hexosaminidase $\mathrm{C}, O$-GlcNAcase (OGA) removes this sugar moiety from proteins. $O$-GlcNAcylation can modulate protein functions in analogy to protein phosphorylation, and has been shown to be involved in almost all cellular processes including signal transduction and regulation of gene expression (see recent reviews $[4,22,30]$. An interesting finding is that $O$-GlcNAc and phosphate moieties can compete for the same or neighboring protein residues resulting in a complex interplay between the types of post-translational modification [3, 29].

\section{The O-GIcNAc, a cellular 'rheostat'}

The cycling of addition and removal of $O$-GlcNAc is comparable, in the time scale, to that of phosphorylation and dephosphorylation. However, there exists a fundamental difference between the two types of modification: while phosphorylation is regulated by hundreds of specific kinases and phosphatases, $O$-GlcNAcylation is irrespective of the target protein. The primary function of $O$-GlcNAcylation is thought to be the modulation of cellular processes in response to nutrients and to cellular stress. The modulation of protein functions by $O$-GlcNAcylation, however, is different in nature from phosphorylation. By analogy to an electrical circuit, the phosphorylation events represent "microswitches," which turn on or turn off protein activity. In contrast, $O$-GlcNAcylation represents a "rheostat", an adjustable resistor used in applications that require the adjustment of current or the varying of resistance in an electric circuit. Therefore, rather than controlling specific proteins, i.e. "microswitches", $O$-GlcNAcylation can tune the overall cellular processes to accommodate nutrient status and cellular stress [10].

The overall activity of OGT is regulated linearly by a wide range of intracellular concentrations of UDP-GlcNAc [15], which fluctuates in turn proportionally in response to the flow of nutrients (glucose, glutamine, energy) or stress [19]. Thus, the $O$-GlcNAcylation can play as a 'metabolic and stress sensor' by modulation of diverse proteins with just two enzymes (i.e., OGT and OGA) to adjust to the nutritional or stress status of the cell.

\section{Is O-GlcNAc final modification?}

Theoretical consideration I: O-GlcNAc is $\beta$ - anomer, the right configuration for NAGK substrate

In the early step of UDP-GlcNAc biosynthesis, GlcNAc is phosphorylated to GlcNAc-6-phosphate (GlcNAc-6-P) by $N$-acetylglucosamine kinase (GlcNAc kinase or NAGK; EC 2.7.1.59). By GlcNAc-6-P mutase, GlcNAc-6-P is converted to GlcNAc-1-P, which is coupled to UTP to produce UDP-GlcNAc. Phosphorylation of monosaccharide GlcNAc by NAGK is well known. On the other hand, it is an intriguing question to ask whether the O-GlcNAc, which is linked to the hydroxyl group of Ser or Thr of a protein, can serve as a substrate for NAGK. To answer this question it is most important to find the configuration of $O$-GlcNAc. Applying saturation transfer difference NMR experiments on human NAGK, Blume et al. [2] found that NAGK exhibits a high preference for $\beta$-anomeric GlcNAc over other monosaccharides. Since $O$-GlcNAc transferase (OGT) also uses $\beta$-anomeric substrate, i.e $O-\beta$ - $N$-acetyl glucosamine, the $O$-GlcNAc is linked to a serine or threonine in $\beta$ -configuration, which is the right anomeric configuration for a NAGK substrate (Fig. 1). Therefore, $O$-GlcNAc may serve as substrates for NAGK.

Theoretical consideration $\|$ O-GlcNAc orientation and steric hindrance may not be a problem

Many different mammalian NAGK species were characterized $[1,5,7]$. Rat liver NAGK is a homodimer of $39 \mathrm{kDa}$ subunits [13], and the human NAGK cDNA encodes a predicted molecular mass of $37.4 \mathrm{kDa}$ [12]. Weihofen et al. [28] elucidated crystal structures of homodimeric human NAGK in complexes with either GlcNAc or $\mathrm{ADP} /$ glucose. Unfortunately, they failed to crystallize a complex with both substrates, GlcNAc and ATP. Nonetheless, based on the two crystal structures, which they succeeded to determine, they established a 3D model for a NAGK complex with GlcNAc and ATP (Fig. 2). In this model, the $N$-terminal small and C-terminal large domains form a " $\mathrm{V}$ "-shaped structure, which acts as an active center for binding GlcNAc and ATP.

In order for NAGK to bind its substrate GlcNAc, the $O$-GlcNAc must be presented in the right orientation, the $\mathrm{C} 6-\mathrm{OH}$ group of the glucopyranose pointing deep into the "V" valley. This means that the local structure of a substrate peptide with $O$-GlcNAc should be oriented such that the 

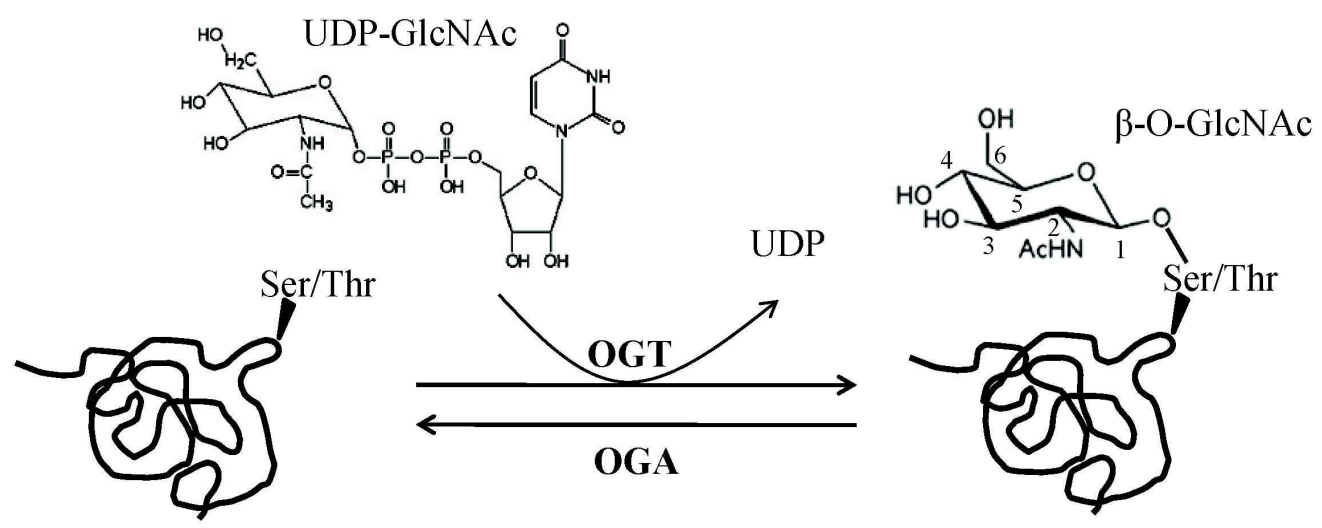

Fig. 1. The OGlcNAc modification. OGT couples GlcNAc moiety of UDP-GlcNAc to the hydroxyl group of a serine or threonine residue of a protein. The $\mathrm{C} 1$ hydroxyl group of GlcNAc moiety is $\beta$-anomeric, same as the monomer substrate GlcNAc for NAGK, which phosphorylates on its C6 hydroxyl group. The Ser/Thr-linked GlcNAc is called OGlcNAc. The removal reaction is catalysed by OGA.

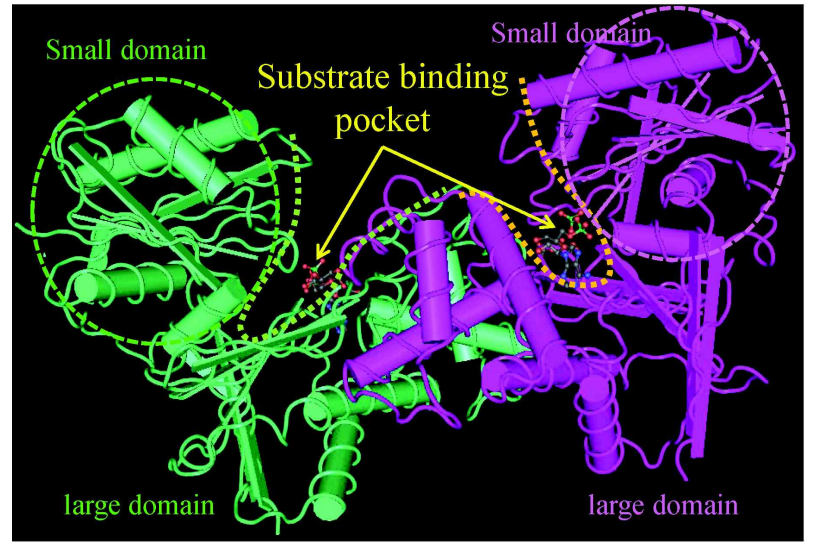

Fig. 2. Three-Dimensional representation of human NAGK in complex with ADP and glucose. NAGK forms a dimer in the cell (green and pink colors), through interaction of large domains. Beween the small (broken circles) and large domain is " $\mathrm{V}$ " valley (broken curves) which is the substrate binding pocket. The 3D structure was from Weihofen et al. [28].

GlcNAc moiety thrust into the "V" pocket of NAGK. The -OH group of serine/threonine residues on a substrate protein is coupled to $\mathrm{C} 1-\mathrm{OH}$ group of UDP-GlcNAc's $\beta$ -D-glucopyranose, so that the $\mathrm{C} 6-\mathrm{OH}$ group is positioned in the free end side. When a substrate peptide thrusts into the " $\mathrm{V}$ " pocket, this is the right orientation as a natural monomer GlcNAc positions in the active site (Fig. 3). Another critical criterion for suitability of $O$-GlcNAc as a NAGK substrate is whether the " $\mathrm{V}$ " valley is spacious enough to avoid steric hindrance by the nearby structures surrounding the target $O$-GlcNAc peptide. Although no 3D structure of an
A C6'-OH: coupled to $\gamma-\mathrm{P}$
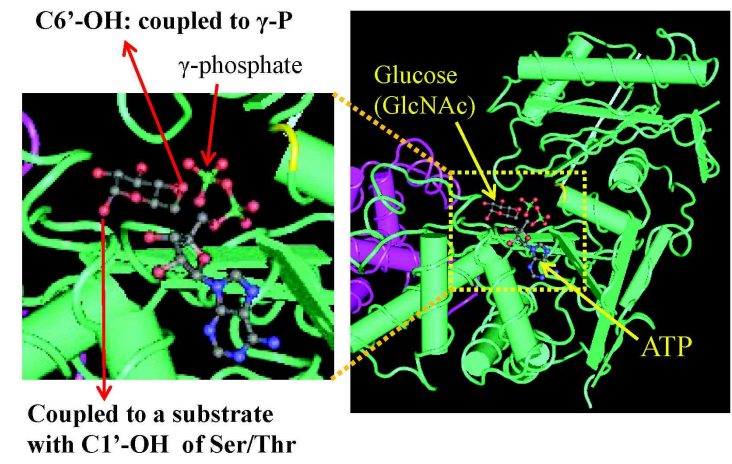

B
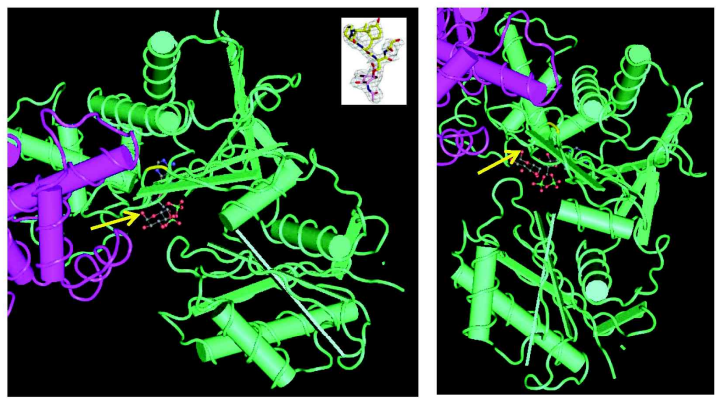

Fig. 3. Crystal structures of the "V" valley of human NAGK in complex with ADP and Glucose. The orientation of substrates and the C1, C6 hydroxyl groups of glucose, and 8 -phosphate of ATP are marked (A). Two examples of images viewed at different directions are shown (B). The in inset in B is the 3D structure of TAB1 O-GlcNAc peptide in the similar size dimension as the NAGK. Note that "V" valley is spacious enough to accommodate the $O$-GlcNAc substrate peptide. Adapted from Weihofen et al. [28].

$O$-GlcNAc bound NAGK complex is available at the present time, it can be simulated by putting the structure of substrate 
peptide into the "V" valley of NAGK's substrate binding site. Taking advantage of the 3D viewing program $\mathrm{CN} 3 \mathrm{D}$ (version 4.3) we can view the crystal structure of human NAGK in complex with ADP and glucose [28] (NCBI MMDB ID: 41376PDB ID: 2CH6, http://www.ncbi.nlm.nih.gov/ Structure $/ \mathrm{mmdb} / \mathrm{mmdbsrv}$.cgi? Dopt=s\&uid=41376). As shown in Fig. 3, the "V" pocket of NAGK active site was predicted spacious enough to allow the $O$-GlcNAc substrate peptide to thrust into. Therefore, it can be anticipated that a substrate protein can present its $O$-GlcNAc moiety into the " $\mathrm{V}$ " pocket in the right orientation deep enough to place it on the GlcNAc binding site without steric hindrance.

Theoretical consideration III: actin's O-GlcNAc protrudes out of the peptide backbone

As is explained so far, it is essential requirement that a target $O$-GlcNAc peptide thrust out of the periphery. We examined through $O$-GlcNAc databases if this is the case. Contractile proteins actin and myosin are $O$-GlcNAcylated [11]. The crystal structure of the Drosophila 5C cytoplasmic actin with point mutations A204E/P243K (AP-actin) was determined in complex with cytochalasin D [20]. Actins are well conserved proteins and the Drosophila 5C actin is > $98 \%$ identical with human 8 -cytoplasmic actin. The rat actin is O-GlcNAcyated on Ser198 [11], which corresponds to Ser199 of Drosophila 5C actin. The peptide loop containing Ser199 is positioned on the surface of the global protein (Fig. $4 \mathrm{~A})$. When viewed in various rotations, it is evident that the local loop as well as its regional domain protrudes out to periphery (Fig. 4B). Unfortunately, we could not find any other 3D structures of $O$-GlcNAc proteins. However, the
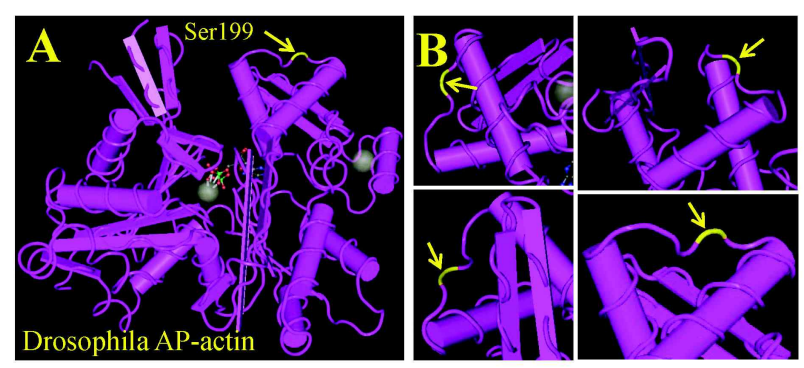

Fig. 4. Crystal structures of Drosophila 5C cytoplasmic actin (AP-actin). The position of O-GlcNAc modified amino acid Ser199 was indicated by yellow color (arrow) in the whole molecule. Different views at various directions by rotating the molecule are shown (B). Note that the OGlcNAc target peptides are protruding out to the surface of the molecule. Adapted from Nair et al. [20]. actin's case strongly indicates that at least some $O$-GlcNAc would serve as substrates for NAGK.

\section{Theoretical consideration IV: possible substrate} compatibility of O-GlcNAc peptides

The target loop containing $O$-GlcNAc protrusion must be such a dimension as to fit the substrate binding " $\mathrm{V}$ " pocket of NAGK. Since there is no such data available so far, we inferred the possible compatibility from several known $O$-GlcNAc peptides. Schimpl et al. [24] reported the molecular details of the interaction of a bacterial $O$-GlcNAcase (OGA) homolog with three different synthetic $O$-GlcNAcpeptides derived from characterized $O$-GlcNAc sites in the human proteome; p53 (Ser149 [29]), TAK1-binding protein 1 (TAB1, Ser395 [25]), and hOGA itself (Ser405 [17]). The crystal structures of these peptides in complexes with the Clostridium perfringens OGA (CpOGA) was determined (Fig. 5A). The peptides bind a conserved OGA substrate binding groove with similar orientation and conformation (Fig. 5A; a, b, c). An important fact in our side of view is that, in addition to extensive contacts with the sugar, the OGA recognizes the peptide backbone. This fact indicates that the target $O$-GlcNAc peptides thrust deep into the substrate binding pocket of OGA, which, in turn, suggests that the local domain containing $O$-GlcNAc moiety thrust deep enough into the " $V$ " valley of NAGK.

The deep thrust into the substrate binding pocket of OGA was well expected by the 3D structure of OGT, the first enzyme in $O$-GlcNAc cycling. The crystal structure of human OGT in complex with UDP-GlcNAc was determined by Lazarus et al. [16]. As shown in Fig. 5B, the binding site for UDP-GlcNAc is very deep in the protein. The deep position of the OGT's substrate binding site requires the target $O$-GlcNAc peptides to thrust out far from the protein's surface. Therefore, the $O$-GlcNAc cycling is, in nature, likely to occur on the peptides that protrude far out of the surface.

\section{Experimental Evidence |: AP180 contains the} O-GlcNAc-P mass, $\mathrm{m} / \mathrm{z} 284$

The first experimental evidence for the phosphorylation of $O$-GlcNAc was found by Graham et al. [8]. Assembly protein AP180, which is modified with both phosphate and $O$-GlcNAc, is involved in the assembly of clathrin coated vesicles in synaptic vesicle endocytosis. To determine the sites for phosphorylation and $O$-GlcNAcylation of the protein, they analysed rat brain AP180 phosphopeptides and 

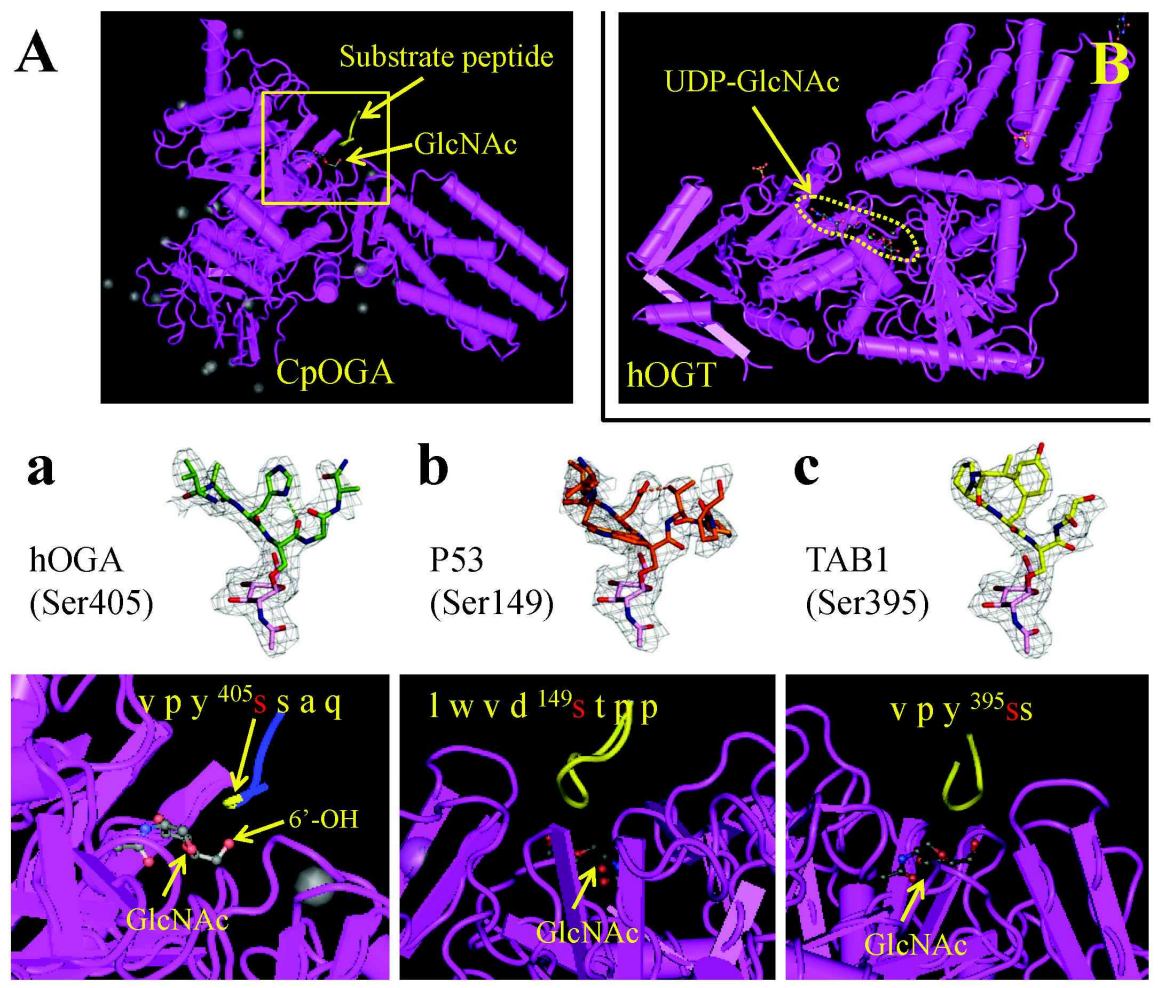

Fig. 5. Crystal structures of OGT and OGA showing their substrate binding pockets. The OGA structure in complex with its substrate GlcNAc peptide (A) and OGT structure with UDP-GlcNAc (B) are shown. The enlarged views of the OGA crystal structures with different substrate peptides in $O$-GlcNAcylated states were shown in the insets of A $(\mathrm{a}, \mathrm{b}, \mathrm{c})$. Note the space large enough to allow the thrust of substrate peptides (insets of A) and deep positioning of UDP-GlcNAc in OGT substrate binding pocket (B). See details in the text. Adapted from Schimpl et al. [24] for Clostridium perfringens OGA (CpOGA) and Lazarus et al. [16] for human OGT (hOGT) in complexes with different known O-GlcNAc substrate peptides.

O-GlcNAc modified peptides by LC-MS/MS. To their surprise, they noticed that the more abundant signal at $\mathrm{m} / \mathrm{z}$ 284 accounted for the difference between the nonmodified (M, $1545 \mathrm{Da})$ and modified AP180 305-320 (M, $1828 \mathrm{Da})$ peptide by $O$-GlcNAc-P (Fig. 6A). A detailed analysis showed that the signal at $\mathrm{m} / \mathrm{z} 284$ is $O$-GlcNAc-P at Thr-310. The Thr-310 was either found in naked or $O$-GlcNAcylated or $O$-GlcNAc-P, but not phosphorylated alone (Fig. 6B). Interestingly, the flanking amino acids Ser306 and Ser313 were phosphorylated. A sequence with a high homology to AP180 305-320 was repeated in the C-terminal portion AP180 598-630. In this region, Ser621 and Ser627 were also phosphorylated (Fig. 6B). However, due to the low signal strength, they were unable to confirm the $O$-GlcNAcylation of Ser625. The interaction or cooperation of $O$-GlcNAc-P with nearby phosphorylation sites will offer diverse leverage for the control of such proteins. Multiple phospho-sites increase net negative charge and hydrophilicity. $O$-GlcNAc also increases hydrophilicity and therefore will affect the sol-
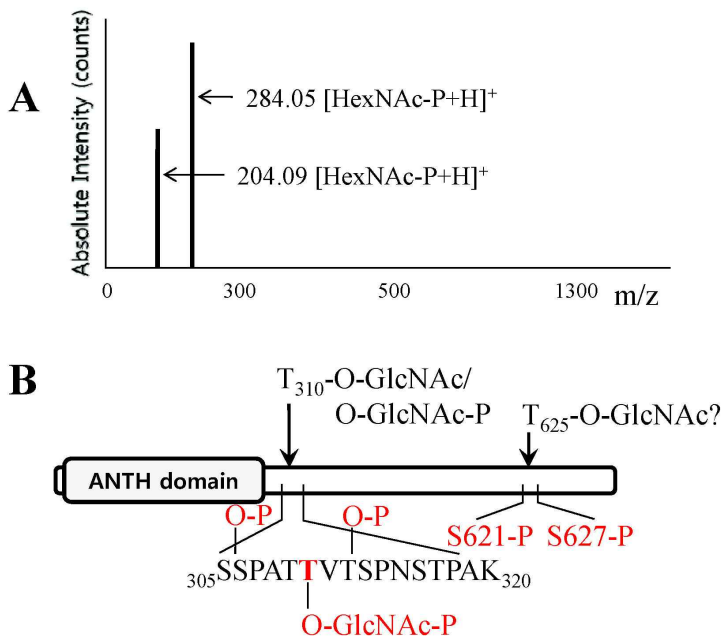

Fig. 6. AP180 is modified by O-GlcNAc-P. A simplified MS profile shows two m/z (A). The m/z 284 and m/z 204 signals represents $O$-GlcNAc-P and $O$-GlcNAc, respectively at Thr-310. The local sequence including Thr310, phospho-sites flanking it, and a homologous sequence with potential O-GlcNAc site (T625) with flanking phospho-sites are marked. Adapted from Graham et al. [8]. 
ubility and binding characteristics with other proteins. Subtle changes in the protein's character will be used to fine-tune its function to the fluctuation of the cellular physiology.

\section{Experimental Evidence $\|$ : NAGK increases the} phospho-signal of some select 0 -GlcNAc proteins

Our laboratory set out to identify potential $O$-GlcNAc-P proteins by proteomics. To minimize artificial inefficiency in the phosphorylation process we took advantage of cell cultures. The human embryonic kidney (HEK293T) cells were transfected with wild-type (pDsRed2-NAGK ${ }_{W T}$ ) or mutant (pDsRed2-NAGK ${ }_{\text {D107A }}$ ) NAGK-expression vectors. The D107A point mutated NAGK retained almost no enzyme activities (manuscript in preparation). As reported in Moon et al. [18], we found some of the phospho-signal increased proteins by NAGK overexpression were $O$-GlcNAc proteins. In brief, comparison of 2D-gel spots of pDsRed2NAGK $_{W T}$-transfected HEK293T cell extract with pDsRed2-

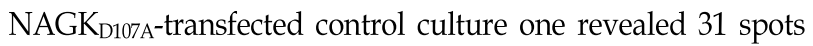
with altered phospho-signals. By eliminating spots that showed drastic increase or decrease in the protein amounts, we selected 7 spots for determination of protein identity. Among the 6 proteins, which we succeeded in ID determination, 4 of them were $O$-GlcNAcylated, and one was glycosylated. Furthermore, to prove the credibility of the data, the $4 O$ GlcNAc protein spots were duplicates of the same two proteins, two $\mathrm{HSP} 90 \beta$ and two enolase 1 (ENO1) spots. The Ser ${ }^{43}$ and Ser ${ }^{452}$ of Hsp90 $\beta$ and the Ser ${ }^{461}$ of Hsp90a are $O$-GlcNAcylated [23]. The $\mathrm{Ser}^{452}$ is also a phosphorylation site [6]. Since ENO1 was reported to be phosphorylated by PKC [21], these proteins are probably another examples of complex interplay between phosphorylation and $O$-GlcNAcyation.

\section{Existence of 'O-GlcNAc-P'om'? What does it} mean?

The cycling of $O$-GlcNAcylation is peculiar in that it is regulated by just two enzymes, OGT and OGA. In contrast to phosphorylation cycling, which is regulated by numerous specific kinases and phosphatases, $O$-GlcNAcylation is irrespective of the target protein. Therefore, the primary function of $O$-GlcNAcylation is thought to adjust cellular processes in response to nutrients and to cellular stress. Therefore, rather than turning on or off of a single protein's function (i.e., "microswitch"), $O$-GlcNAcylation is well

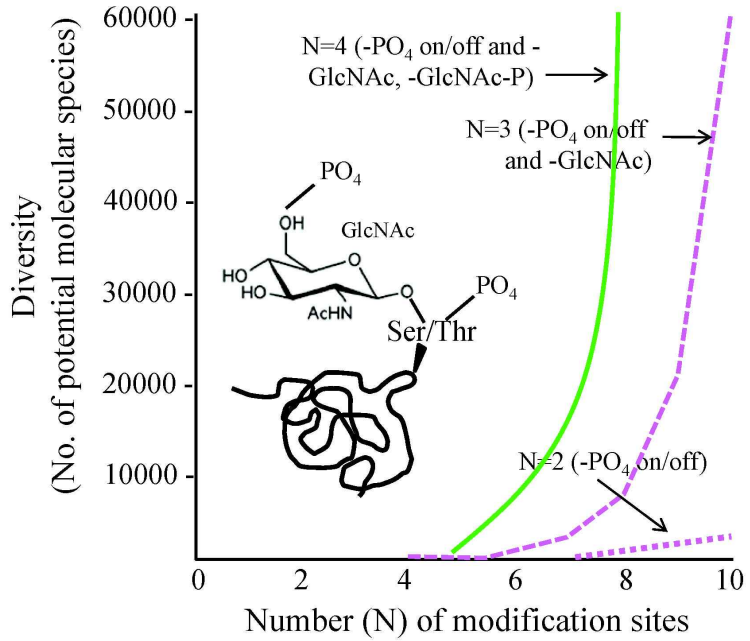

Fig. 7. A graph showing the theoretical numbers of different molecular modifications of a protein. The inset shows the 4 levels of a model protein; naked, phospho-, $O$-GlcNAc, and $O$-GlcNAc-P. Note the number of possible modification increases enormously with an additional leverage. The vast capacity for subtle modification of proteins will permit 'analogue' control of their activities. Adapted from Hart et al. [10].

adapted to control the overall flow rate of cellular signal transduction, because it requires only two enzymes to be controlled. By analogy to an electrical circuit, $O$ GlcNAcylation plays as a "rheostat" that is used to tune the rate of overall cellular processes to accommodate nutrient status and cellular stress [10]. Supporting this inference, the overall activity of OGT is regulated linearly by the concentrations of UDP-GlcNAc [15]. Since the concentration of UDP-GlcNAc sensitively fluctuates in response to the flow of nutrients (glucose, glutamine, energy) or stress $[19$, the $O$-GlcNAcylation can play as a "rheostat" to quickly adjust cellular processes to fluctuating energy and stress level.

The $O$-GlcNAc "rheostat" works in combination with phosphorylation. This combination will offer diverse leverage for the control over $O$-GlcNAc proteins (Fig. 7). This system is not binary with an 'on' or 'off' state for each signalling molecule but is 'differential'. By adding another control tool ' $O$-GlcNAc-P', this system can set the flow rate of cellular processes at enormously diverse levels. Diverse changes in the protein's character will adjust the cell to the subtle fluctuation of the cellular physiology. Such wide diversity will represent the continuous 'analogue' control of cellular processes instead of digital step-wise jump in the control. 


\section{Conclusion and prospect}

$O$-GlcNAcylation is a moon-lightening signal controlling mechanism, which emerges only recently. The system is simple being controlled by only two enzymes. This, in turn, is a good evolutionary adaptation to quickly accommodate a cell to moment-moment fluctuating intra- and extracellular microenvironments. The O-GlcNAc "rheostat" would be much more delicately control the efficacy of signal transduction by adding another control lever, the phosphorylation of $O$-GlcNAc. It can be inferred that the key regulatory proteins in each signal transduction may be the target $O$-GlcNAc to be phosphorylated. These strategic proteins may constitute the $O$-GlcNAc-P group, dubbed ' $O$ GlcNAc-P'om'. Characterization of $O$-GlcNAc-P'om will shed lights on our understanding normal and pathophysiology of cellular responses.

\section{Acknowledgement}

This research was supported by Basic Science Research Program through the National Research Foundation of Korea (NRF) funded by the Ministry of Education, Science and Technology (grant number 2012006116).

\section{References}

1. Allen, M. B. and Walker, D. G. 1980. Kinetic characterization of N-acetyl-D-glucosamine kinase from rat liver and kidney. Biochem 185, 577-582.

2. Blume, A., Berger, M., Benie, A. J., Peters, T. and Hinderlich, S. 2008. Characterization of ligand binding to $\mathrm{N}$-acetylglucosamine kinase studied by STD NMR. Biochem 47, 13138-13146.

3. Copeland, R. J., Bullen, J. W. and Hart, G. W. 2008. Cross-talk between GlcNAcylation and phosphorylation: roles in insulin resistance and glucose toxicity. Am J Physiol Endocrinol Metab 295, E17-E28.

4. Darley-Usmar, V. M., Ball, L. E. and Chatham, J. C. 2012. Protein O-linked $\beta$-N-acetylglucosamine: a novel effector of cardiomyocyte metabolism and function. J Mol Cell Cardiol $52,538-549$.

5. Datta, A. 1970. Studies on hog spleen $N$-acetylglucosamine kinase. I. Purification and properties of $N$-acetylglucosamine kinase. Biochem Biophys Acta 220, 51-60.

6. Dephoure, N., Zhou, C., Villén, J., Beausoleil, S. A., Bakalarski, C. E., Elledge, S. J. and Gygi, S. P. 2008. A quantitative atlas of mitotic phosphorylation. Proc Natl Acad SCi USA 105, 10762-10767.

7. Gindzienski, A., Glowacka, D. and Zwierz, K. 1974.
Purification and properties of $N$-acetylglucosamine kinase from human gastric mucosa. Eur J Biochem 43, 155-160.

8. Graham, M. E., Thaysen-Andersen, M., Bache, N., Craft, G. E., Larsen, M. R, Packer, N, H. and Robinson, P. J. 2011. A novel post-translational modification in nerve terminals: $O$-linked $N$-acetylglucosamine phosphorylation. J Proteome Res 10, 2725-2733.

9. Hahne, H., Sobotzki, N., Nyberg, T., Helm, D., Borodkin, V. S., van Aalten, D. M., Agnew, B. and Kuster, B. 2013. Proteome Wide Purification and Identification of O-GlcNAc-Modified Proteins Using Click Chemistry and Mass Spectrometry. J Proteome Res 12, 927-936.

10. Hart, G. W., Slawson, C., Ramirez-Correa, G. and Lagerlof, O. 2011. Cross talk between O-GlcNAcylation and phosphorylation: roles in signaling, transcription, and chronic disease. Annu Rev Biochem 80, 825-858.

11. Hédou, J., Bastide, B., Page, A., Michalski, J. C. and Morelle, W. 2009. Mapping of $O$-linked beta- $N$-acetylglucosamine modification sites in key contractile proteins of rat skeletal muscle. Proteomics 9, 2139-2148.

12. Hinderlich, S., Berger, M., Schwarzkopf, M., Effertz, K. and Reutter, W. 2000. Molecular cloning and characterization of murine and human $\mathrm{N}$-acetylglucosamine kinase. Eur $J$ Biochem 267, 3301-3308.

13. Hinderlich, S., No "hring, S., Weise, C., Franke, P., Sta"sche, D. and Reutter, W. 1998. Purification and characterization of $N$-acetylglucosamine kinase from rat liver. Eur J Biochem 252, 133-139.

14. Hu, P., Shimoji, S. and Hart, G. W. 2010. Site-specific interplay between O-GlcNAcylation and phosphorylation in cellular regulation. FEBS Lett 584, 2526-2538.

15. Kreppel, L. K. and Hart, G. W. 1999. Regulation of a cytosolic and nuclear $O$-GlcNAc transferase. Role of the tetratricopeptide repeats. J Biol Chem 274, 32015-32022.

16. Lazarus, M. B., Jiang, J., Gloster, T. M., Zandberg, W. F., Whitworth, G. E., Vocadlo, D. J. and Walker, S. 2012. Structural snapshots of the reaction coordinate for O-GlcNAc transferase. Nat Chem Biol 8, 966-968.

17. Lazarus, M. B., Nam, Y., Jiang, J., Sliz, P. and Walker, S. 2011. Structure of human O-GlcNAc transferase and its complex with a peptide substrate. Nature 469, 564-567.

18. Marshall, S., Nadeau, O. and Yamasaki, K. 2004. Dynamic actions of glucose and glucosamine on hexosamine biosynthesis in isolated adipocytes: differential effects on glucosamine 6-phosphate, UDP-N-acetylglucosamine, and ATP levels. J Biol Chem 279, 35313-35319.

19. Moon, I. S. and Lee, H. 2013. Identification of potential substrates of $N$-acteylglucosamine kinase by proteomic approach. J Life Sci In press.

20. Nair, U. B., Joel, P. B., Wan, Q., Lowey, S., Rould, M. A. and Trybus, K. M. 2008. Crystal structures of monomeric actin bound to cytochalasin D. J Mol Biol 384, 848-864.

21. Nettelblad, F. A. and Engström, L. 1987. The kinetic effects of in vitro phosphorylation of rabbit muscle enolase by protein kinase C. A possible new kind of enzyme regulation. FEBS Lett 214, 249-252. 
22. Ngoh, G. A., Facundo, H. T., Zafir, A. and Jones, S. P. 2010. O-GlcNAc signaling in the cardiovascular system. Circ Res 107, 171-185.

23. Overath, T., Kuckelkorn, U., Henklein, P., Strehl, B., Bonar, D., Kloss, A., Siele, D., Kloetzel, P. M. and Janek, K. 2012. Mapping of $O$-GlcNAc sites of $20 \mathrm{~S}$ proteasome subunits and Hsp90 by a novel biotin-cystamine tag. Mol Cell Proteomics 11, 467-477.

24. Schimpl, M., Borodkin, V. S., Gray, L. J. and van Aalten, D. M. 2012. Synergy of peptide and sugar in O-GlcNAcase substrate recognition. Chem Biol 19, 173-178.

25. Schimpl, M., Schüttelkopf, A. W., Borodkin, V. S. and van Aalten, D. M. 2010. Human OGA binds substrates in a conserved peptide recognition groove. Biochem J 432, 1-7.

26. Torres, C. R. and Hart, G. W. 1984. Topography and polypeptide distribution of terminal $N$-acetylglucosamine residues on the surfaces of intact lymphocytes. Evidence for O-linked GlcNAc. J Biol Chem 259, 3308-3317.
27. Wang, Z., Gucek, M. and Hart, G. W. 2008. Cross-talk between GlcNAcylation and phosphorylation: site-specific phosphorylation dynamics in response to globally elevated O-GlcNAc. Proc Natl Acad Sci USA 105, 13793-13798.

28. Weihofen, W. A., Berger, M., Chen, H., Saenger, W. and Hinderlich, S. 2006. Structures of human $N$ Acetylglucosamine kinase in two complexes with $N$-Acetylglucosamine and with ADP/glucose: insights into substrate specificity and regulation. J Mol Biol 364, 388-399.

29. Yang, W. H., Kim, J. E., Nam, H. W., Ju, J. W., Kim, H. S., Kim, Y. S. and Cho, J. W. 2006. Modification of p53 with O-linked $\mathrm{N}$-acetylglucosamine regulates p53 activity and stability. Nat Cell Biol 8, 1074-1083.

30. Zachara, N. E., O'Donnell, N., Cheung, W. D., Mercer, J. J., Marth, J. D. and Hart, G. W. 2004. Dynamic O-GlcNAc modification of nucleocytoplasmic proteins in response to stress. A survival response of mammalian cells. J Biol Chem 279, 30133-30142.

\title{
초록 : ‘O-GICNAc-P'om'의 존재 가능성
}

\author{
문일수 ${ }^{1,2} \cdot$ 이현숙 ${ }^{2} \cdot$ 이형종 ${ }^{3}$ \\ (동국대학교 ${ }^{1}$ 의과대학 해부학교실, ${ }^{2}$ 의학연구소, ${ }^{3}$ 산부인과학교실)
}

OGlcNAc 화(O-GlcNAcylation)는 단백질의 serine이나 threonine에 $N$-acetylglucosamine (GlcNAc) 분자가 결 합하는 것으로, 기존의 당단백질과 달리 세포질 및 핵단백질 모두에 일어난다. 또한 수정의 속도가 빠르고 가역적 으로 일어남이 인산화 수식과 유사하다. 그러나 수많은 인산화효소와 탈인산화효소가 관여하는 것과 달리 $O$ GlcNAc 수식은 $O$-GlcNAc transferase (OGT)와 $O$-GlcNAcase (OGA) 단 두 개의 효소에 의하여 이루어진다. 이러한 단순한 조절기전은 세포가 내외환경에 즉시 적응할 수 있도록 진화한 것으로 해석된다. 즉, $O \mathrm{GlcNAc}$ 수식은 특정한 단백질 하나 하나의 활성을 켜거나 끄는 것이 아니라, 세포의 신호전달과정의 효율을 전반적으로 조절하는 '가변저항기(rheostat)' 역할을 한다. $O$ GlcNAc 수식은 흔히 같은 아미노산 혹은 그 주변의 아미노산이 인산화되는 것을 수반하는데, 이는 인산화와 함께 서로 조화를 이루어 세포활성을 조절하는 것으로 해석된다. 최근 $O-G l c N A c$ 이 더 나아가 $O$-GlcNAc-P로 인산화될 가능성이 제시되고 있는 바, 본 총설에서는 이의 가능성을 이론적으로 설명하고, 실제 실험결과를 소개한다. 